\title{
ESTUDIO EXPERIMENTAL SOBRE LA DINÁMICA POSTDEPOSITACIONAL EN RASTROS DE USO: INTEGRIDAD ARTEFACTUAL DEL COMPONENTE 1 DE CUEVA MARIPE (SANTA CRUZ, ARGENTINA)
}

\author{
VIRGINIA LYNCH", MARILÉN FERNÁNDEZ"* \& LAURA L. MIOTTI ${ }^{\cdots * *}$
}

\begin{abstract}
RESUMEN
Los materiales recuperados de excavaciones arqueológicas han sido afectados por diversos procesos post-depositacionales; ya sea de carácter natural como así también antrópico. Estos procesos ocasionan traslados y reorganización de los objetos alterando, en gran medida, la integridad de los mismos. En tal sentido, la evaluación de los múltiples procesos culturales y naturales que intervienen en la formación de los depósitos arqueológicos, es una herramienta fundamental para inferir las condiciones que contribuyeron a la formación de los sitios arqueológicos en general. Los objetos líticos tallados son indicio material, a partir del cual, se pueden realizar estudios de procesos de formación y comportamiento del registro arqueológico mediante análogos experimentales. En este caso, el objetivo del trabajo ha sido profundizar los conocimientos acerca de estos procesos y de su accionar sobre los rastros de uso detectados en los artefactos líticos del sitio arqueológico Cueva Maripe (Santa Cruz, Argentina), con ocupaciones humanas desde inicios del Holoceno. La acción del agua como agente corrosivo pudo haber influenciado las modificaciones de las superficies y filos del material lítico, afectando diferencialmente el grado de preservación de los microrrastros en los distintos sectores de la cueva. Para evaluar la variabilidad funcional de artefactos, presentamos los resultados obtenidos de la aplicación de dos vías analíticas independientes: análisis funcional y análisis diatomológico.
\end{abstract}

PALABRAS CLAVES: cazadores-recolectores, procesos post-depositacionales, análisis funcional, diatomeas.

\section{EXPERIMENTAL STUDY ABOUT THE DYNAMIC OF POSTDEPOSITACIONAL PROCESSES ON USE TRACES: ARTEFACTUAL INTEGRITY OF COMPONENTE 1 IN MARIPE CAVE SITE (SANTA CRUZ, ARGENTINA)}

\author{
ABSTRACT \\ The materials recovered from archaeological excavations, has been affected by different post- \\ * División de Arqueología, Museo de Ciencias Naturales, La Plata-UNLP. Paseo del Bosque s/n CP 1900, La Plata (Argentina) \\ lynchvirginia@gmail.com. \\ * Laboratorio de Geomorfología y Cuaternario, CADIC-CONICET, 9410, Ushuaia, Tierra de Fuego, Argentina. shanamain@ \\ gmail.com. \\ División de Arqueología, Museo de Ciencias Naturales, La Plata-UNLP. Paseo del Bosque s/n CP 1900, La Plata (Argentina) \\ laura.miotti2@gmail.com.
}


depositional processes, whether natural or anthropic. This processes results in transfer, mix and reorganization of the objects limiting to a large extent, the integrity thereof. In this sense, the assessment of multiple cultural and natural processes involved in the formation of archaeological deposits, is essential to infer the conditions that contributes to the formation of archaeological sites in general. The stone tools are the material sign from which can begin the study of site formation processes and their behavior on archaeological record by experimental analogue. Thus, the objective of this study was to deepen the knowledge about these processes and their actions on the use traces found in lithic artifacts recovered from the Maripe Cave (Santa Cruz, Argentina) archaeological site with human occupations since early Holocene. The action of water as modifying agent may have influenced the changes of the surfaces and edges of stone tools, affecting differentially the conservation degree of micro-wear traces in different sectors of the cave. To assess the functional variability of artifacts, we present the results applying two independent studies: functional and diatom analysis.

KEY WORDS: hunter-gatherers, lithic taphonomy, micro-wear analysis, diatoms.

\section{INTRODUCCIÓN}

Desde el proceso de producción, uso y descarte de un artefacto hasta el momento de recuperación del mismo por parte de los arqueólogos, ha pasado un período considerable de tiempo. Durante este período la superficie de los artefactos estuvo expuesta a numerosos daños y transformaciones, consecuencia directa de factores ambientales como culturales.

Estas modificaciones pueden ser vistas, de acuerdo a su grado de desarrollo, tanto a ojo desnudo (fracturas, fisuras, craquelados, pulido, brillo, cambio de color de las piezas), como así también microscópicamente (con altos y bajos aumentos).

Pero, ¿cuál es la importancia del estudio de estos procesos? ¿Cuáles son las causas de las modificaciones que se generan por el accionar de los mismos en los artefactos líticos? ¿Es posible determinar algún patrón en estas modificaciones que afecten de manera desigual a los rastros que se originan por el uso de un instrumento? Estas han sido algunas de las preguntas que diversos investigadores han tratado de resolver (Rottländer, 1975; Vaughan, 1981; Mansur-Franchomme, 1983, 1986; Plisson, 1983; Plisson \& Mauger, 1988; Levi Sala, 1993; entre otros).

Siguiendo a Levi-Sala (1993, 1996), estos procesos comprenden cierta variabilidad y se encuentran expresados a partir de la formación de pátinas, lustres, puntos brillantes, daño del filo y estrías. Sin embargo, la génesis de estas modificaciones es muy compleja y puede incluir factores mecánicos (movimientos verticales $u$ horizontales de las piezas o como consecuencia del contacto entre ellas), como también químicos (presencia o ausencia de agua, cambios en la alcalinidad $u$ acidez del sustrato, entre otros).

Los rastros de uso sobre diferentes materiales suelen ser afectados por estos procesos, como en el caso de los micropulidos (modificaciones superficiales de los granos de cuarzo por disolución de parte de la sílice que compone la estructura superficial en sectores localizados del filo, a consecuencia de la fricción y el dislocamiento producidos por el trabajo, -Anderson-Gerfaud 1980, 1981, Mansur-Franchomme 1981, 1983a y b, 1986 y bibliografía allí citada-). Estos pueden ser modificados por diferentes factores y su preservación en el contexto arqueológico dependerá de: la dureza del material trabajado, la presencia de agua u otros líquidos agregados o contenidos en el material trabajado, la presión ejercida, tipo de materia prima y tamaño de grano, presencia de abrasivos y tiempo de uso.

Otros autores como Kaminska y colaboradores (1993) han señalado que el análisis minucioso de los procesos post-depositacionales también permiten determinar la homogeneidad del sedimento en el que se encuentra enterrado un artefacto, brindando información adicional acerca de la cronología relativa de un sitio y de factores ambientales que pudieron haber intervenido luego de la depositación de los materiales.

Por otro lado, Anderson-Gerfaud (1981) y Keeley (1981) se vieron en la necesidad de investigar acerca de las diferentes alteraciones 
naturales, ya que gran número de sus piezas presentaba un marcado lustre sobre su superficie, imposibilitando la aplicación del análisis funcional. Ellos definieron tres tipos de alteraciones para indicar aquellas piezas posibles de ser observadas: a) daño del filo b) superficies brillantes y c) presencia de pátinas blancas. El primero se refiere a un marcado esquirlamiento del filo dificultando la observación de microrrastros, debido a que, se habría removido partes del filo trabajado. A su vez, la observación de superficies brillantes en una pieza determinada se relaciona directamente a ataques químicos y mecánicos naturales, tales como la solifluxión, percolación del agua y acción eólica (Röttlander, 1975; Stapert, 1976; Keeley, 1980); mientras que la presencia de patinas tiene orígenes diversos y puede presentarse con diferentes grados de desarrollo, afectando áreas localizadas del filo o sobre toda la superficie del artefacto.

Otro aporte igualmente importante a esta temática, fueron las investigaciones desarrolladas por Plisson y Mauger en 1988, centrando su interés en las modificaciones que ocasionan a los rastros generados por el uso de un instrumento. En principio, consideran que estas alteraciones no son lo suficientemente intensas como para enmascarar los micropulidos originados por uso, sin embargo, posteriormente, enfatizan las complicaciones que causan tanto en estrías como en micropulidos, llegando en algunos casos a desaparecer.

En nuestro país, el estudio minucioso y sistemático acerca de estos procesos, fue realizado por varios investigadores a partir de la observación del material lítico arqueológico (caso de Los Toldos y El Ceibo- Mansur-Franchomme, 1983, 1986; Casa del Minero 1 -Paunero \& Castro, 2001-; Túnel I -Álvarez, 2003-; Arroyo Seco 2- Leipus, 2006- y el sitio Laguna La Barrancosa 1 -Pal, 2008-). Sin embargo, las causas que originan estos procesos, muchas veces como consecuencia de modificaciones químicas en contextos arqueológicos, fueron escasamente abordadas mediante análogos experimentales (MansurFranchomme, 1983, 1987).

Por lo tanto, teniendo en consideración que los conjuntos suelen ser evidencia modificada debido a su calidad de "expuesto" a agentes y procesos post-depositacionales, la observación, identificación y registro de diferentes tipos de alteraciones naturales ocasionadas por la permanencia de los materiales sobre superficie, sirven como vía de contrastación para inferir procesos de formación de sitios. De acuerdo con esto, el análisis funcional de base microscópica realizado sobre los materiales recuperados del sitio Cueva Maripe (Prov. De Santa Cruz, Argentina), específicamente del Componente 1 (ca. 9.500 años AP), ha arrojado un bajo porcentaje de rastros de uso asociados al trabajo sobre cuero y material blando animal en toda la secuencia de ocupación, lo que ha llevado a plantear ciertos interrogantes acerca del estado de conservación de los materiales analizados. Es en este sentido, que nos preguntamos si estos bajos porcentajes son consecuencia directa de la falta de uso sobre este tipo de material o debido a un estado diferencial de conservación de estos rastros de acuerdo a las características microambientales de las cámaras en las que se encuentra dividida Cueva Maripe. Por otro lado, la presencia de lustres y formación de pátinas blancas principalmente en el sector sur, sumado a condiciones de mayor humedad en esta cámara (presencia de agua que podría haber ocasionado cambios en el $\mathrm{pH}$ de los sedimentos), llama la atención y resulta un elemento disparador para indagar acerca de la génesis de estas alteraciones y los efectos que ocasionan en el grado de preservación de posibles rastros de uso en materiales líticos a partir de análogos experimentales. En este trabajo se tratarán exclusivamente las modificaciones químicas que podrían haber ocasionado la formación de pátinas y lustres sobre las superficies de los instrumentos líticos considerados.

Por lo tanto, en relación a esta temática se han propuesto los siguientes objetivos: a) Establecer la integridad artefactual de los materiales líticos asociados a las ocupaciones iniciales del sitio arqueológico Cueva Maripe y observar mediante distintos atributos (pátinas y lustres) los efectos de procesos post-depositacionales que afectaron los materiales. b) Indagar mediante análogos experimentales (inmersión en soluciones químicas) las posibles causas de las modificaciones identificadas y el grado de preservación de los rastros de uso. c) Explorar a partir del análisis diatomológico otras vías que permitan comprender las posibles causas de alteración del material lítico en el contexto de estudio. 


\section{ALTERACIONES NATURALES IDENTIFICADAS EN MATERIALES ARQUEOLÓGICOS}

Las alteraciones post-depositacionales se producen en distintos contextos sedimentarios, durante la permanencia de los materiales en la superficie del terreno como resultado de procesos erosivos, generalmente meteóricos, generando graves daños sobre las piezas (MansurFranchomme, 1983).

El grado e intensidad de cada uno de estos procesos que afectan a los materiales líticos dependerá de un conjunto de factores, tales como la materia prima utilizada en su elaboración, las características litológicas de los depósitos que las contienen y de los procesos microerosivos involucrados (Levi-Sala, 1993). Dentro de las más comunes, se encuentran la presencia de pátinas blancas o amarillentas, las cuales son producto del proceso de disolución o precipitación en medio húmedo o ácueo post-depositacional, generando a nivel microscópico una cubierta o delgada capa que opaca las superficies líticas e impide la observación completa de la microtopografía de los artefactos (Mansur-Franchomme, 1986, 1987, 1999).

Cuando los artefactos carecen de patinas, es frecuente observar otros tipos de modificaciones como lustres y puntos brillantes. La presencia de lustres ha sido definida dentro del análisis funcional como una "patina brillante", a menudo asociada al lustre del suelo, que se encuentra en la mayoría de las piezas arqueológicas (Mansur-Franchomme, 1983, 1986). Muchos investigadores consideran que el lustre puede ser atribuido a procesos mecánicos (pulido ocasionado como consecuencia de una matriz de arena y al movimiento del sedimento) y químicos (su apariencia lisa podría ser resultado de procesos químicos ocasionados en el sedimento). A nivel óptico, aparece uniforme sobre la superficie de los instrumentos, mientras que microscópicamente se puede observar con mayor intensidad sobre el filo o superficies altas de la microtopografía de las piezas, variando en grosor, desde fina a muy brillante y espesa (Levi Sala, 1993).

Los denominados puntos brillantes fueron observados por primera vez por Semenov (1964) y posteriormente por Shepherd (1972). Se caracterizan por ser un pulido altamente brillante sobre la superficie de un artefacto, de diferentes dimensiones; desde un pequeño punto hasta extenderse sobre toda la pieza. No poseen relación directa con el filo utilizado, por lo que deben ser excluidos como rastros de uso, en especial cuando se encuentran aislados.

También se pueden nombrar otras modificaciones como el "barniz del desierto" (producto de la formación de un depósito mineral de hierro y magnesio) que da un aspecto asimismo brillante a las superficies líticas; rodamientos (fenómenos de disolución y deformación de la superficie ocasionados por sedimentos arenosos o gravas); eolización (alteración de la superficie silícea debido al choque de materiales aportados por el viento generando una película de sílice amorfa); pisoteo y movimientos de suelo (provocando esquirlamientos de los filos y estrías ubicadas de manera azarosa acompañadas por zonas de abrasión localizadas) (Mansur et al. 2007).

$\mathrm{Si}$ bien estas modificaciones pueden brindar información acerca del medio en el que fueron enterrados los materiales y de los distintos procesos que ocurrieron a posteriori, suelen generar grandes complicaciones a la hora de realizar estudios más específicos como aquellos relacionados a la funcionalidad de los instrumentos líticos. Es por esta razón, que una mayor comprensión acerca del proceso de formación y efectos de estas alteraciones mediante piezas experimentales, es de fundamental importancia a la hora de realizar tales estudios sobre materiales líticos arqueológicos. Es a partir de este postulado que en los siguientes apartados se profundiza este cuestionamiento y se complementa con los resultados obtenidos de las diferentes alteraciones identificadas a partir del análisis funcional de base microscópica de materiales líticos recuperados del sitio Cueva Maripe.

\section{ESTRUCTURA GENERAL DEL SITIO Y GEOARQUEOLOGÍA}

Cueva Maripe se encuentra ubicada sobre el curso medio del cañadón La Primavera (Santa Cruz, Argentina). La cueva está dividida en dos Cámara Norte (CN) y Sur (CS) por un tabique rocoso, y ambos sectores difieren en sus 
características micro-ambientales como así también en sus contextos arqueológicos. Se trata de un sitio multicomponente con ocupaciones desde el Pleistoceno final al Holoceno tardío (Miotti et al. 2007, 2014) (Fig.1).

La secuencia cultural de la cueva indica una

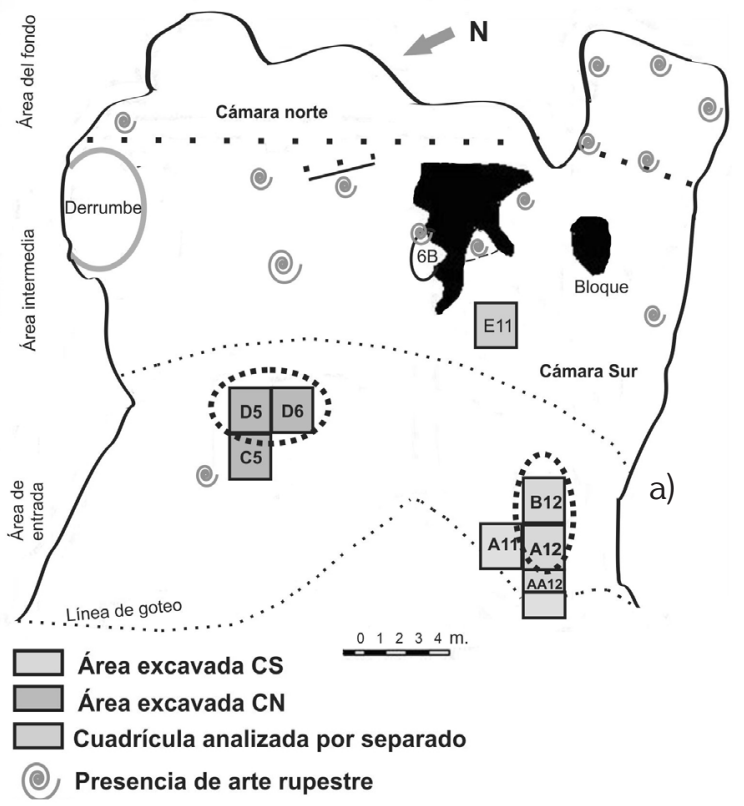

alta redundancia ocupacional evidenciada a partir de la presencia de abundantes restos materiales (artefactos líticos y óseos, restos faunísticos y vegetales, arte mobiliar y pigmentos) y es por este motivo que fue considerado un sitio de uso principalmente residencial (Miotti et al. 2007; Hermo, 2008; Carden, 2009; Lynch, 2013, 2014; Lynch \& Hermo, 2015). Sin embargo, los contrastes que presenta Cueva Maripe en cuanto a la secuencia de materiales en estratigrafía y microambientales en las dos cámaras, generó la hipótesis de uso diferencial de sectores dentro de la cueva (Miotti et al. 2007; Hermo, 2008; Miotti \& Marchionni, 2009). Por esta razón, se realizaron diferentes análisis a partir de distintos marcos de referencia (SIG intrasitio, geoarqueología, secuencia radiocarbónica, tafonomía y zooarqueología y tecnología lítica), con el fin de poder ajustar la resolución temporal y generar un conocimiento más acabado en cuanto a las ocupaciones humanas en el sitio y al poblamiento del área investigada (Miotti et al. 2014).

Los recientes estudios, han permitido identificar 6 capas estratigráficas en ambos sectores, 3 de las cuales presentan material arqueológico (Miotti et al. 2014).

Fig. 1 a-b. Dibujo en planta y fotografía del sitio arqueológico Cueva Maripe. c. Detalles de la estratigrafía, de las cuadrículas analizadas (en línea punteada) y de los fechados obtenidos de Cámara Norte.
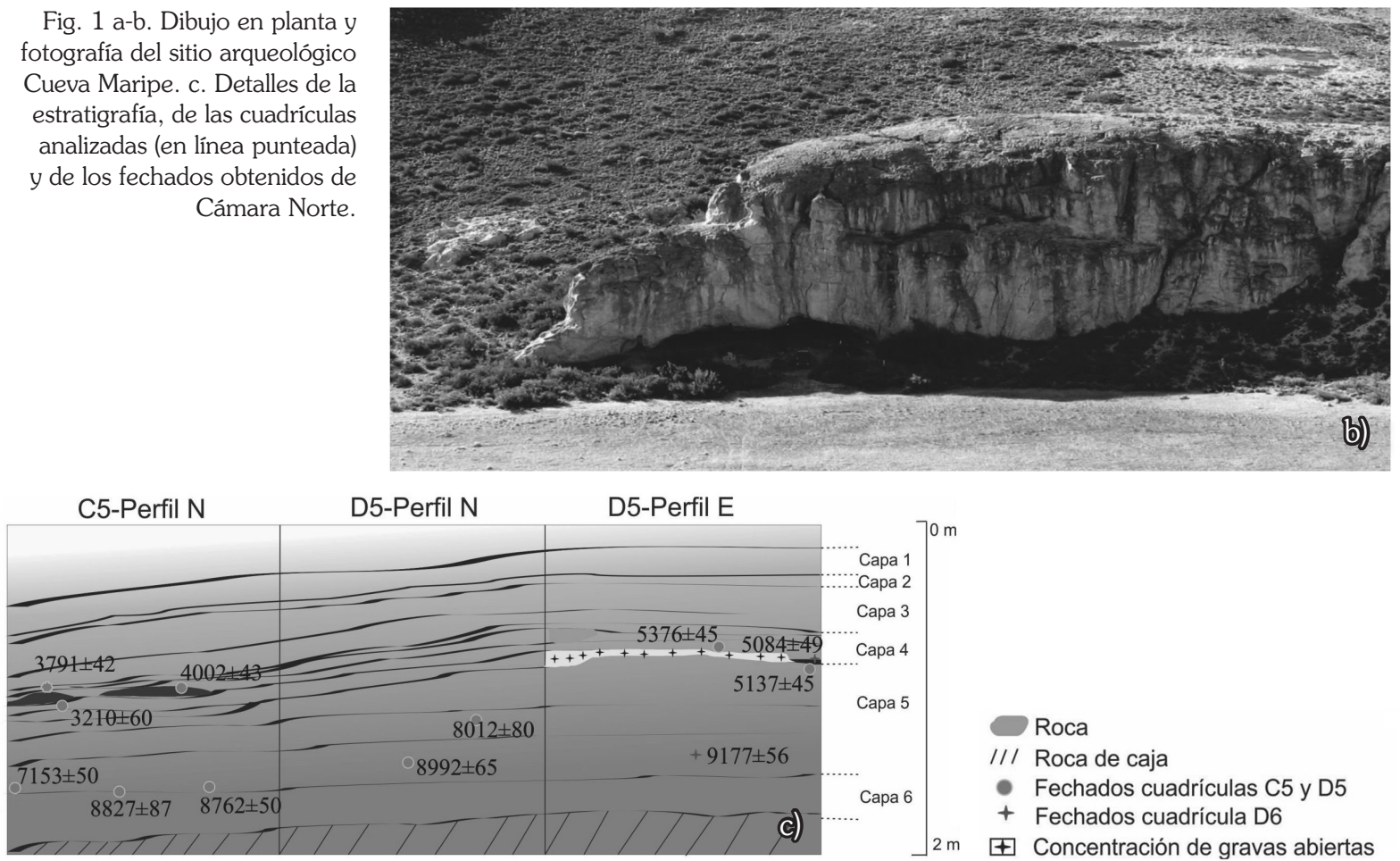
De esta manera, la secuencia estratigráfica de Cámara Norte se compone de: la Capa 1 que representa la superficie actual y está conformada por sedimento eólico, con aporte de la roca de caja (tobas de la Formación Chön Aike, Panza, 2001) y de estiércol de bóvidos; por debajo se extiende la Capa 2, que corresponde a un evento de quemazón de la cueva en momentos históricos (Miotti et al. 2007). Estas unidades apoyan sobre los estratos que poseen contenido arqueológico prehispánico (Capas 3, 4 y 5). La Capa 3 (de 43 $\mathrm{cm}$ de espesor y con un $\mathrm{pH}=7,7$, cuadrícula D5 perfil $\mathrm{N}$ ) corresponde a un sedimento psefítico, en matriz arenosa color gris claro; presenta clastos mayores muy angulosos que provienen del techo de la cueva. Esta capa se acuña hacia el sur. La Capa 4 es similar a la 3 con un $\mathrm{pH}=7,8$ (D5, perfil $\mathrm{N}$ ), aunque su textura es levemente más gruesa y presenta un alto contenido de carbones. La Capa 5 comienza a $83 \mathrm{~cm}$ de la superficie del suelo actual, presenta un $\mathrm{pH}=8,4$ (D5, perfil $\mathrm{N}$ ) y se divide en cuatro subcapas (a, b, c y d). La subcapa $5 a$ presenta grava abierta de ignimbritas con clastos de basaltos subordinados, abundantes carbones esparcidos lateralmente. En un sector del perfil la grava pasa a un sedimento fino que corresponde a un fogón. Se observa una fina capa de restos vegetales. Por último la Capa $6(\mathrm{pH}=9,2$, cuadrícula D5 perfil $\mathrm{N}$ ) corresponde a una arena eólica, arqueológicamente estéril, relacionada con el final de la secuencia sedimentaria de la cueva y corresponde a la disgregación de la roca de base (Miotti et al. 2014; Mosquera 2014) (Ver Fig.1).

Por el contrario, la Cámara Sur, presenta una menor tasa de sedimentación que ha permitido una difusa diferenciación en capas. Este sector posee un aporte de humedad efectiva mayor que la Cámara Norte, debido a las presencia de un manantial hacia la pared del fondo de la cueva. Actualmente, este manantial, se encuentra con baja actividad, provocando encharcamientos intermites en la zona más interna de esta cámara, sin alcanzar a escurrir hacia la boca de la misma, sector externo, donde fueron practicadas las excavaciones.

La secuencia estratigráfica de Cámara Sur fue descripta por Rabassa (Rabassa et al. 2007) a partir del perfil sur de las cuadrículas A12 y B12. La Capa 1 está conformada por la acumulación de guano de ganado perteneciente a momentos históricos en que la cueva fue utilizada como corral, la Capa 2 disminuye la concentración de guano siendo muy inferior a Capa 1 . Hay guano quemado y con cierta laminación que puede deberse a una mayor humedad de este sector de la cueva. La Capa 3 presenta aproximadamente $19 \mathrm{~cm}$ de espesor con una medición de $\mathrm{pH}=8,6$ (perfil Sur de las cuadrículas A12 y B12), es un limo areno-arcilloso con alto contenido de moteados negros y castaño rojizo (alteración de guano y raíces). Laminación de ámbito palustre color gris verdoso a castaño amarillento a gris ocráceo decolorándose en la base. No tiene guijarros. Aparece en la base un color castaño oscuro, casi negro. Estos niveles negros húmicos se extienden hacia abajo con el aporte de guijarros de tamaño cada vez mayor. El sedimento amarillento en seco, se muestra con precipitación de sales, indicando condiciones de humedad local (posible pantano). Capa 4: la caracteriza una matriz limo-arenosa con clastos óseos y carbones. Tiene un gran porcentaje de materia orgánica. Muestra laminación $(\mathrm{pH}=9,5$, perfil Sur de las cuadrículas A12 y B12). Apoya sobre unidad 5. Capa 5: matriz de arena fina con gran contenido de guijarros. Presenta dos subcapas: Subcapa 5a $(\mathrm{pH}=9,2)$ : contiene fogones, es de color gris claro con presencia de clastos de roca de caja. Subcapa $5 \mathrm{~b}(\mathrm{pH}=7,1$, perfil Sur de las cuadrículas A12 y B12): de color pardo y disminuye la concentración de clastos de la roca de caja. Capa 6: Arena eólica, arqueológicamente estéril. Los clastos de roca de caja de CS son más redondeados que los de la CN. Esto podría deberse a la mayor humedad de este sector de la cueva, lo que a su vez habría influido en la compactación de este sector y la formación del "pantano" representado en la Capa 3.

\section{LINEAMIENTOS METODOLÓGICOS}

El accionar de las alteraciones en las piezas líticas se evaluó analíticamente a partir de diferentes variables, tanto a nivel arqueológico como también a partir de un programa experimental. En cuanto al análisis realizado sobre las piezas recuperadas del sitio Cueva Maripe, se tuvo en cuenta el tipo de artefacto, materia prima utilizada en su producción, cantidad de piezas alteradas, grado y tipo de alteración registrada.

A nivel experimental, se evaluó la incidencia 
de un medio acuoso con $\mathrm{pH}$ extremos sobre piezas experimentales trabajadas en diferentes materiales y estados. Si bien los alcances y limitaciones de las experiencias replicativas ya ha sido indicado en trabajos anteriores (Mansur-Franchomme, 1983; Álvarez, 2003; Leipus, 2006; Nami, 2011), creemos que en determinados estudios no deja de ser una vía analítica que permite generar explicaciones alternativas en un registro arqueológico complejo como el de Cueva Maripe.

Por lo tanto, la serie experimental incluyó 27 lascas elaboradas principalmente sobre ignimbritas silicificadas, procedentes de la región de estudio, materia prima microcristalina al igual que otras presentes en el registro (calcedonia y xilópalo) y mayormente utilizada en la manufactura de artefactos líticos recuperados en la estratigrafía de Cueva Maripe. Las piezas fueron trabajadas sobre diferentes materiales y estados: blando (cuero seco y gramíneas), semiduro (madera no estacionada) y duro (material óseo en estado fresco). El tiempo de uso empleado fue de 60' cada pieza con el fin de generar rastros diagnósticos del material trabajado. Se realizó un registro fotográfico de cada pieza luego de haber sido utilizada. Posteriormente, fueron introducidas en soluciones químicas con $\mathrm{pH}$ extremos: solución ácida ( $\mathrm{pH}$ : 4,3- $\mathrm{H}_{2} \mathrm{O}$ desmineralizada y $\mathrm{HCL}$ ), solución alcalina ( $\mathrm{pH}$ : 8,9-1M $\mathrm{NaHCO}_{3}+$ exceso $\mathrm{CaCO}_{3}$ y $\mathrm{NaOH}$ ) y solución neutra ( $\mathrm{pH}$ : 7,4$\mathrm{H}_{2} \mathrm{O}$ desmineralizada) (Ver Tabla 1). Durante la experimentación se registró la constancia del pH mediante un peachímetro Pometer pH-009 (I) y el estado de cada pieza anterior a su uso y luego del mismo a partir de fotomicrografías realizadas a través de un microscopio metalográfico Nikon Epiphoto 200 (aumentos de 50X-500X)-. Una vez sumergidas en las soluciones, se procedió a realizar un seguimiento fotográfico mediante la observación semanal de las piezas experimentales durante tres meses para corroborar cambios significativos sobre las superficies de las mismas. Para esto se tuvo en consideración una serie de variables de acuerdo a los medios ópticos utilizados. A nivel macroscópico, -a ojo desnudo o mediante lupa binocular,- se registró la presencia de restos de carbonatos, desarrollo de lustre o redondeamiento de superficies o aristas. Y a nivel microscópico, se identificó la presencia de hoyuelos, desarrollo de pátinas blancas, lustres, puntos brillantes y modificaciones ocasionadas sobre rastros de uso (en distintos tipos de micropulidos o en el desarrollo de estrías).

Por otro lado, los estudios diatomológicos fueron incluidos en este trabajo ya que las alteraciones identificadas podrían estar influenciadas por las condiciones ambientales de depositación (i.e. presencia de agua que podría ocasionar cambios en la composición del pH del sedimento en las distintas cámaras de Cueva Maripe).

Para llevar a cabo este análisis se tomaron muestras de sedimento de cada capa de las

Tabla 1. Artefactos formatizados en relación a las materias primas utilizadas en cada cámara. AFS: artefacto con formatización sumaria, BF: bifaz, CFR: cuchillo con filo retocado, CÑ: cuña, CP: cepillo, FND: filo no diferenciado, LR: lámina retocada, MUR: muesca con retoque, RD: raedera, RP: raspador, UF: unifaz y PF: punta de proyectil.

\begin{tabular}{|cccc|}
\hline $\begin{array}{c}\text { Solución/ } \\
\text { Mat.Trab. }\end{array}$ & $\begin{array}{c}\text { Alcalina } \\
(p H .9,6)\end{array}$ & $\begin{array}{c}\text { Ácida } \\
(p H .4,3)\end{array}$ & $\begin{array}{c}\text { Neutra } \\
(p H .7,6)\end{array}$ \\
\hline MD-V & EP5 (RP) & EP17 (RP) & EP28 (RP) \\
EP6(AS) & EP36 (AS) & EPS) \\
\hline H & EP9 (RP) & EP20 (RP) & EP32 (RP) \\
\hline EP10 (AS) & EP21(AS) & EP33 (AS) \\
\hline G & EP2 (RP) & EP13 (RP) & EP24 (RP) \\
\hline SU & EP46 & EP15 (C) & EP26 (C) \\
\hline Control) & EP47 & EP43 & EP49 \\
& EP48 & EP44 & EP545 \\
\hline Total & N: 9 & N: 9 & N: 9 \\
\hline
\end{tabular}


Tabla 2. Detalles de las piezas experimentales utilizadas: RP: acción de raspado, AS: aserrado, C: corte, MD-V: material duro de origen vegetal, $\mathrm{H}$ : hueso, C: cuero y G: gramíneas y SU: sin uso.

\begin{tabular}{|c|c|c|c|c|c|c|c|c|c|c|c|c|c|c|c|c|c|c|}
\hline \multirow{2}{*}{$\mathrm{AF} / \mathrm{MP}$} & \multicolumn{13}{|c|}{ Cámara Sur } & \multicolumn{5}{|c|}{ Cámara Norte } \\
\hline & AFS & $B F$ & CUR & $C \tilde{N}$ & $C P$ & FND & $L R$ & MUR & $R D$ & $R P$ & $U F$ & $P F$ & TOTAL & $B F$ & $R D$ & $R P$ & $U F$ & TOTAL \\
\hline CG1 & & 1 & 1 & & & & 2 & & 1 & 3 & & & 8 & & & 1 & & 1 \\
\hline ISG1 & 2 & & 1 & 1 & 1 & 2 & & 1 & 2 & 13 & & & 23 & 2 & 2 & 3 & & 7 \\
\hline PG1 & & 1 & 1 & & & & & & & 1 & & 1 & 4 & & & 1 & & 1 \\
\hline XG1 & & & & & 1 & & & & & 2 & & & 3 & & 1 & & 1 & 2 \\
\hline Total & 2 & 2 & 3 & 1 & 2 & 2 & 2 & 1 & 3 & 19 & - & 1 & 38 & 2 & 3 & 5 & 1 & 11 \\
\hline
\end{tabular}

cuadrículas D5 (perfil E; CN) en total 12 muestras, de A11 (perfil SE; CS) en total 3 muestras y del fondo de la cueva (CS), donde se encontró un manantial activo (Miotti et al. 2007) siendo este un lugar con mayor humedad. Para analizar las muestras se realizaron montados permanentes en Naphrax ${ }^{\circledR}$ y se observaron al microscopio óptico con oculares superiores a los 750x. Con el estudio de diatomeas se buscó conocer el tipo de microambientes que predominó en ambas cámaras de la cueva. Principalmente, en la Cámara Sur, donde la presencia de infiltración de agua podría haber modificado o alterado la preservación de los rastros de uso de los materiales líticos en análisis; además la mayor cantidad de materiales arqueológicos estudiados proviene de esta cámara. Sin embargo, no se descartó la posibilidad de encontrar algún tipo de alteración causada por el agua en la Cámara Norte.

\section{SELECCIÓN DE LA MUESTRA ARQUEOLÓGICA Y ANÁLISIS FUNCIONAL}

La muestra estudiada se conformó con el total de artefactos líticos formatizados correspondiente a los niveles iniciales de ocupación de Cueva Maripe -Capa 5 de Cámara Norte, fechada en ca. 8.992 „65 $\mathrm{C}^{14}$ AP y Capa 4 en Cámara Sur con fechados correspondiente a ca. 9.518 $\pm 64 \mathrm{C}^{14}$ AP (Miotti et al. 2007; Hermo, 2008; Miotti at al. 2014). El total de la muestra incluyó 49 piezas, siendo 38 el número registrado en Cámara Sur y 11 artefactos en Cámara Norte (Tabla 2).

Dentro de los grupos tipológicos identificados podemos mencionar que la Cámara Sur presenta una mayor variedad que Cámara Norte. Sin embargo, el porcentaje más elevado, en la Cámara Sur, corresponde al grupo de raspadores ( $n=19,50 \%)$, seguido por cuchillos con filo retocado y raederas $(3=, 8 \%)$, láminas retocadas, cepillos, filos no diferenciados, bifaces $y$ artefactos con formatización sumaria $(n=2$, $5 \%$ ), muescas retocadas, cuñas y perforadores en menores proporciones ( $n=1,3 \%)$.

La Cámara Norte presenta una variedad más acotada; representada por raspadores $(n=5$, $46 \%)$, raederas $(n=3,27 \%)$, bifaces $(n=2,18 \%)$ y un artefacto unifacial que constituye el $9 \%$ de la muestra.

Al ser sometidas al análisis de rastros de uso, el sector norte registró 55\% de piezas con uso seguro, $9 \%$ corresponde a piezas cuyo uso no ha podido ser determinado y $36 \%$ piezas no determinadas por alteración. Mientras que el sector sur presentó $42 \%$ piezas con uso seguro, $23 \%$ no determinadas y $35 \%$ no determinadas por alteración. También se observó exclusivamente que en los niveles inferiores de la Cámara Sur las piezas presentaban un grado de alteración severo con restos de carbonatos y desarrollo de pátinas blancas.

En relación a los recursos procesados, se identificó en la Cámara Norte un 50\% de piezas con micropulidos asociados al trabajo de material duro (madera o hueso), 33\% a material duro de origen animal y $17 \%$ a material duro de origen vegetal. En cuanto a la Cámara Sur, los rastros identificados, corresponden un $66 \%$ a material duro (madera o hueso), $17 \%$ a trabajo sobre cuero y el $17 \%$ restante al trabajo sobre material duro vegetal (madera).

En cuanto a la cinemática empleada, en la Cámara Norte, el mayor porcentaje se encuentra representado por actividades desarrolladas de manera transversal (72\% -raspado o alisado-); mientras que iguales proporciones corresponden 



Fig. 2. Alteraciones post-depositacionales identificadas sobre los materiales recuperados de Capa 4 de Cámara Sur. a. Depositación de carbonatos tanto en cara dorsal como ventral. b. Evidencia de termoalteración (daño térmico).

a acciones longitudinales (corte o aserrado) y no determinables (14\%). En la Cámara Sur incluyó igualmente un mayor porcentaje de acciones transversales (69\%), seguido por acciones longitudinales $(23 \%)$ y bajo porcentaje de no determinadas (8\%).

Las alteraciones registradas en el conjunto de ambas cámaras corresponden principalmente a lustres de suelo, playas de abrasión y puntos brillantes ( $75 \%$ CN y $46 \% \mathrm{CS}$ ) seguido por procesos de termoalteración en la Cámara Norte (25\%), mientras que en el sector sur, se observó otros tipos de alteraciones: presencia de carbonatos (31\%), formación de pátinas blancas (15\%) y procesos de termoalteración (8\%) (Fig.2).

\section{EXPERIMENTACIÓN REPLICATIVA}

La lógica de esta experimentación, como la de otras investigaciones actualísticas, se sustenta en los fundamentos configurativos del plano relacional de la analogía, no en las semejanzas formales entre las acciones del pasado y las realizadas en el presente.

La presencia o ausencia de agua y cambios en la alcalinidad o acidez del sustrato pueden provocar modificaciones en la estructura primaria de las rocas afectando de manera diferencial las trazas de uso (Mansur-Franchomme, 1986; Levi Sala, 1993; Plisson \& Mauger, 1988; entre otros). Dado que se identificaron variaciones en la integridad artefactual y en el grado y tipo de alteraciones identificadas en cada cámara de Cueva Maripe (pátinas blancas y concreciones carbonáticas en Cámara Sur, lustres y puntos brillantes en Cámara Norte), se ha considerado profundizar acerca de la génesis de estas alteraciones mediante análogos experimentales. A continuación se describen los 
resultados obtenidos de las observaciones realizadas (Ver Tabla 1).

\section{Resultados de la experimentación}

- En solución alcalina

A la primera semana de observación el $\mathrm{pH}$ se mantuvo constante $(8,9)$. Luego de su extracción, las piezas fueron lavadas con $\mathrm{H}_{2} \mathrm{O}$ desmineralizada y el filo a observar fue repasado con alcohol para ser visto bajo el microscopio a diferentes aumentos (desde 50X a 500X). Macroscópicamente no habían sufrido ningún tipo de modificación, sin embargo, se observaron restos de la solución de carbonatos en algunos sectores de la microtopografía de las piezas -cara dorsal, zonas de fracturas o de irregularidades de la superficie. No se registró ningún tipo de modificación en los microrrastros generados por uso.

A los 15 días de iniciada la experimentación no se detectó ningún tipo de modificación en las superficies de las piezas a nivel macroscópico. Sin embargo, bajo microscopio metalográfico pudo observarse un incremento de sectores con adhesión de solución carbonática e igualmente en el número de piezas utilizadas en donde aparecieron estos sectores. No se observó presencia de lustres ni cambios en la superficie de los micropulidos ocasionado por el uso del instrumento.

Al mes de observación no se registraron modificaciones macroscópicas. Sí se identificaron a nivel microscópico presencia de restos de solución carbonática en los sectores débiles de la microtopografía de las piezas (fracturas internas). En cuanto a los micropulidos desarrollados por uso no presentaron cambios en los rasgos diagnósticos.

A los dos meses de estar sumergidas, se identificó a nivel macroscópico que las piezas que permanecieron en soluciones alcalinas presentaban una mayor opacidad en sus superficies. Microscópicamente se registró la presencia de concreciones calcáreas en sectores de fracturas y donde no había desarrollo de micropulidos (Fig.3).

En la etapa final de observación (tres meses), la opacidad de las superficies líticas se incrementó notablemente, presentando restos de la solución carbonática a simple vista y el desarrollo inicial de pátinas blancas (se observó cambios en la composición cristalina de la roca) (Fig.4). No se registraron hoyuelos ni lustre sobre la superficie de las piezas, sin embargo, el desarrollo de concreciones carbonáticas, sobretodo en sectores débiles de la microtopografía, pudo ser identificada en la totalidad de los artefactos. Por otro lado, en sectores trabajados y donde había desarrollo de micropulidos, no se registraron depósitos de carbonatos. Este punto permitiría plantear la hipótesis que los micropulidos desarrollados por uso hayan actuado como "capa protectora" frente a un estado extremo de alcalinidad, esto pudo deberse a que en los sectores mencionados la superficie se presenta más lisa y homogénea.

\section{- En solución ácida}

La inmersión en este tipo de solución tuvo el mismo procedimiento de limpieza que en el caso anterior. A la semana de iniciada las observaciones el $\mathrm{pH}$ permaneció constante $(4,3)$. Tanto a nivel macroscópico como microscópicamente no se observaron modificación marcadas de la superficie.

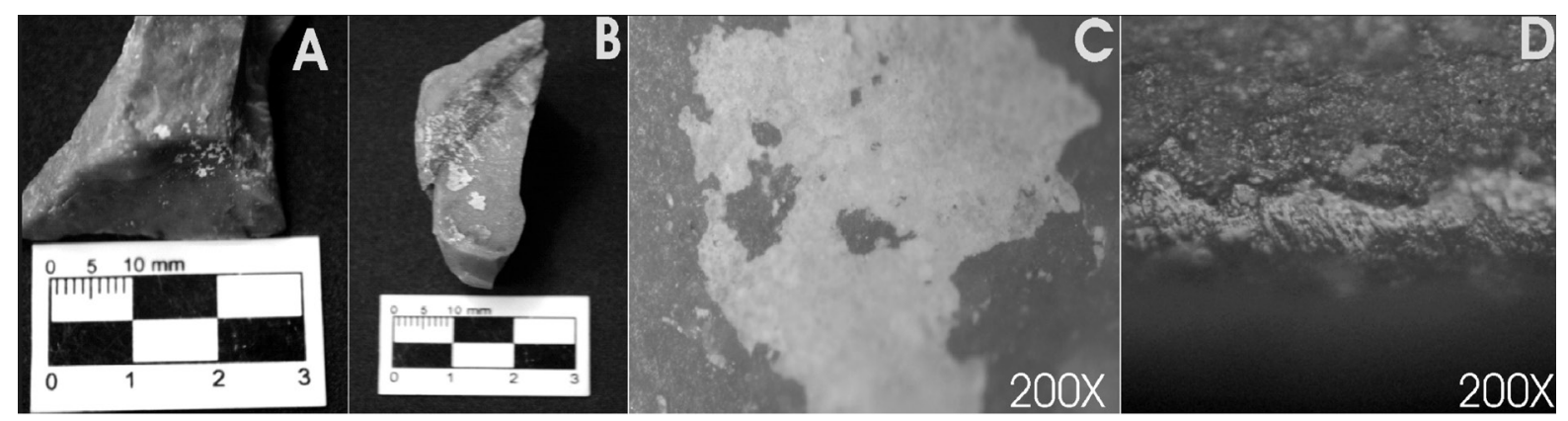

Fig. 3 a-b. Pieza realizada sobre ignimbrita silicificada (EP9), trabajada transversalmente (raspado) sobre material óseo durante 60․ c. Concreción carbonática sobre cara dorsal de la pieza. d. Micropulido de hueso luego de inmersión en solución alcalina durante tres meses, no se observan grandes cambios en sus caracteres diagnósticos (craquelé). 


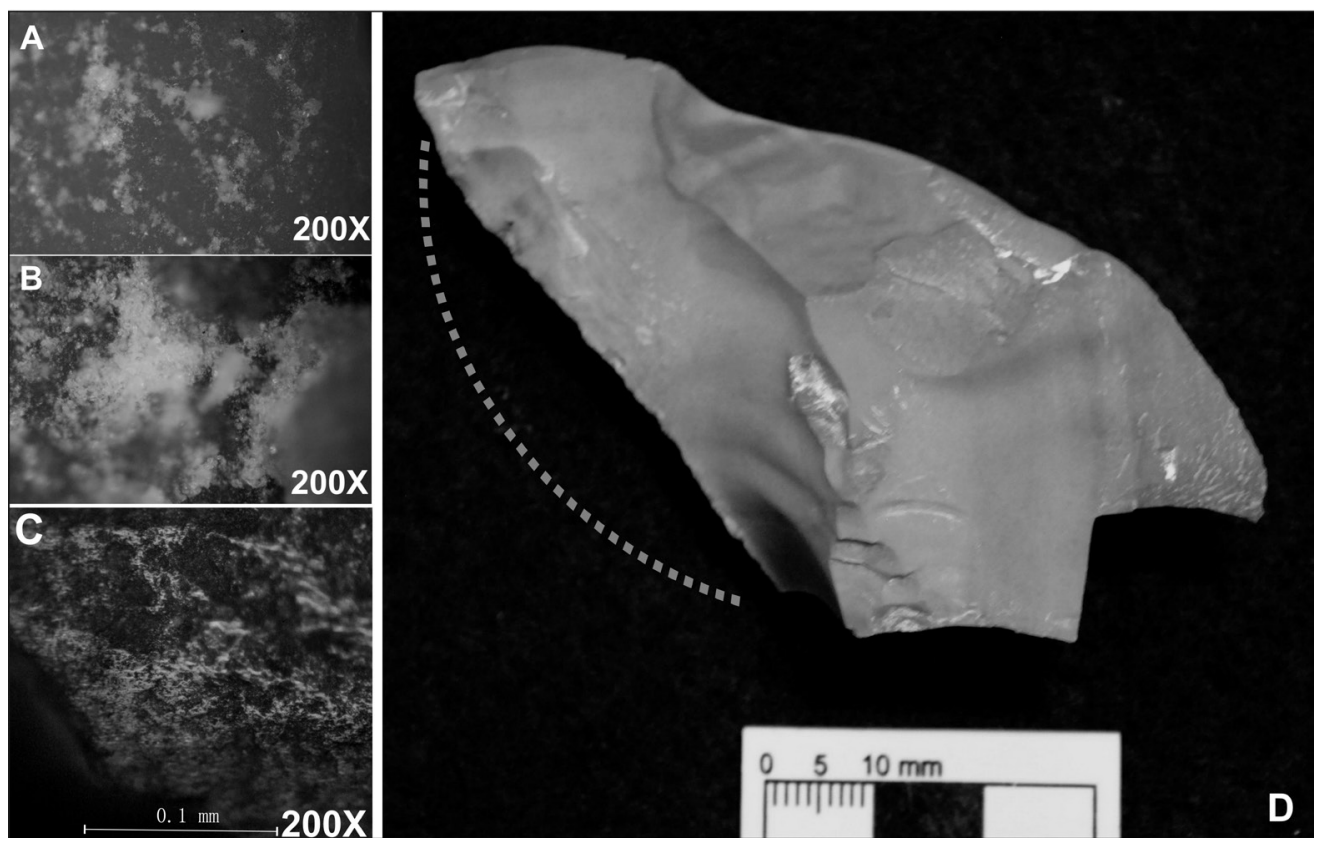

Fig. 4 a-c. Estadio inicial de formación de pátina blanca sobre el filo en sectores no trabajados de la pieza experimental EP6 (trabajada longitudinalmente sobre material duro vegetal) y expuesta a solución alcalina. d. Microfotografía de la pieza EP6 con micropulido de material duro vegetal luego de tres meses en solución alcalina.

A los 15 días de iniciado el tratamiento en soluciones no se reconocieron modificaciones de las piezas a nivel macroscópico. Sin embargo, en algunos casos (EP21, EP13, EP45 y EP43) se registró la presencia de hoyuelos que hasta el momento no habían sido identificados. Asimismo, se observaron sectores con coloración blanquecina sobretodo en fracturas internas de la microtopografía.

Al mes de iniciada la experimentación, no se determinaron modificaciones sobre las superficies de las piezas a nivel macroscópico. Sin embargo, al incrementar el nivel de observación, se reconoció la presencia de hoyuelos en un mayor número de piezas. Por otro lado, también se identificó incremento de sectores con coloración blanquecina sobretodo en áreas de grietas y fracturas internas. En relación a la identificación de cambios en los micropulidos, una sola pieza (EP36) presentó menor volumen y brillo sobre su superficie.

A los dos meses se observó mayor opacidad sobre la superficie de las piezas a nivel macroscópico. Mientras que microscópicamente se mantuvo constante la presencia de hoyuelos. En relación a los rastros de utilización se notaron determinados cambios sobre los micropulidos. En el caso de aquellos originados por el trabajo en hueso, se observó un aplanamiento en el desarrollo del "craquéele", carácter diagnóstico del mismo.

Una vez finalizada la experimentación, se registró a simple vista un incremento en la opacidad de la superficie de las piezas que fueron sometidas a soluciones con acidez extrema. A nivel microscópico se registraron ciertas modificaciones, formación de hoyuelos y cambios en la estructura cristalina (con sectores de coloración blanquecina) (Fig.5). En aquellas que no fueron usadas, estas modificaciones se originaron a lo largo de todo el filo natural. Mientras que en las que fueron trabajadas, su desarrollo se dio en zonas ubicadas hacia el interior del filo y donde no presentaban desarrollo de micropulidos. Por otro lado, también se identificaron cambios sobre los rastros de uso. Luego del tiempo estipulado, el micropulido de cuero esbozó únicamente la presencia de surcos paralelos entre sí, lo que dificultó la identificación concreta del material trabajado. Algo semejante ocurrió con el micropulido de madera, perdiendo brillo y espesor, caracteres diagnósticos de su identificación. Por otra parte, en el caso del 

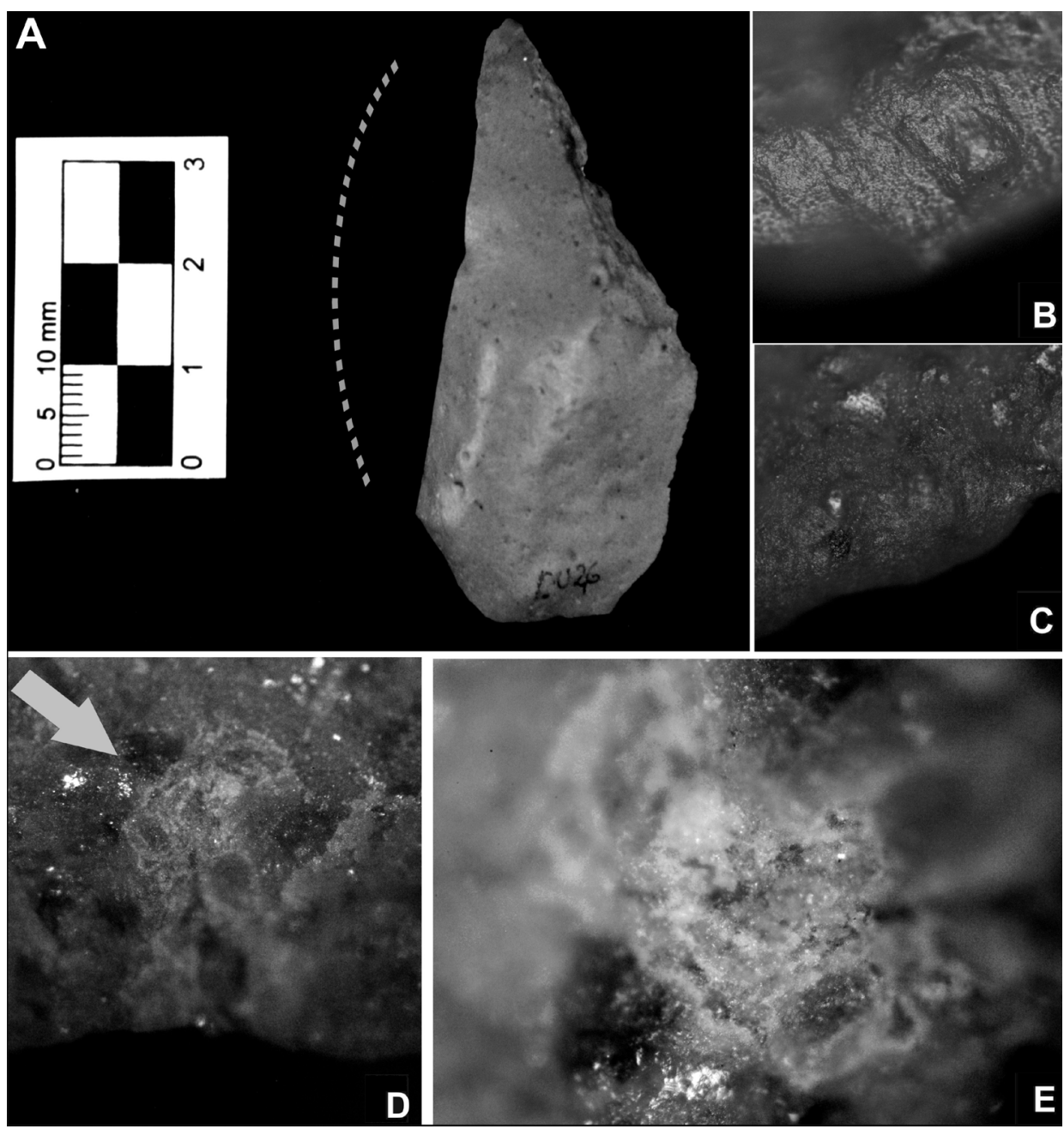

Fig. 5 a-b. Pieza experimental EP13 realizada en ignimbrita silicificada y micropulido generado por el trabajo sobre cuero seco (60') antes de inmersión en solución ácida (aumento 200X). c. Surcos profundos dejados por el trabajo sobre cuero seco (EP13), único rastro presente luego de la inmersión en solución ácida por tres meses (aumento 200X) y d. Desarrollo de sectores con coloración blanquecina sobre la misma pieza (EP13) (aumento 200X).

micropulido de hueso, si bien se observaron cambios sobre su superficie las características principales pudieron ser identificadas.

\section{- En solución neutra}

Las piezas sumergidas en medios con $\mathrm{pH}$ neutro $(7,4)$ tuvieron el mismo tratamiento de limpieza que en los casos anteriores. A la semana de iniciada la observación a nivel macro y microscópico no se observó cambios significativos sobre la superficie de las piezas. El pH se mantuvo constante durante el período de observación, sin embargo no se registró el desarrollo de pátinas ni lustres sobre las superficies e igualmente sobre los micropulidos originados por el trabajo de las piezas sobre distintos materiales. Este punto permite plantear que el factor tiempo probablemente no haya sido suficiente para ocasionar cambios significativos en la estructura cristalina de la roca; o que los catalizadores (ácidos y álcalis) usados como variables en los otros experimentos, hayan acelerado mucho más de lo esperado la modificación de las superficies de los artefactos.

En resumen, el desarrollo inicial de pátinas blancas en sectores "débiles" de la microtopografía 
(fracturas internas) se dio en condiciones extremas de alcalinidad al igual que la depositación en forma de "costra" de carbonatos como habría sido detectado en trabajos anteriores (Levi Sala, 1993). Mientras que las piezas sumergidas en medios con $\mathrm{pH}$ neutro ( $\mathrm{pH}: 7,4)$ no sufrieron alteraciones que pudieran ocasionar cambios significativos de la roca a lo largo del período de observación. En cuanto a la preservación de micropulidos se observó que, en medios ácidos el micropulido de cuero fue el primero en sufrir modificaciones. Luego del tiempo estipulado solo se registraron surcos donde anteriormente se desarrollaba el micropulido de brillo mate y homogéneo sobre la microtopografía de la pieza (Fig. 5). Si bien estos surcos corresponden al carácter diagnóstico del trabajo sobre cuero, por sí solos no permiten realizar la identificación concreta del trabajo desarrollado. Asimismo, los rastros de uso consecuencia del trabajo sobre madera no estacionada sufrieron modificaciones de rasgos que imposibilitaron su determinación, mientras que el de hueso, preservó sus características diagnósticas (Fig.6) al igual que el de gramíneas. En la solución alcalina no hubo cambios significativos sobre los rastros de uso; sin embargo, la depositación de carbonatos sobre el filo dificultó la observación de los microrrastros.

\section{ESTUDIOS DIATOMOLÓGICOS}

El estudio de diatomeas se incluyó en este trabajo como línea de evidencia para corroborar la
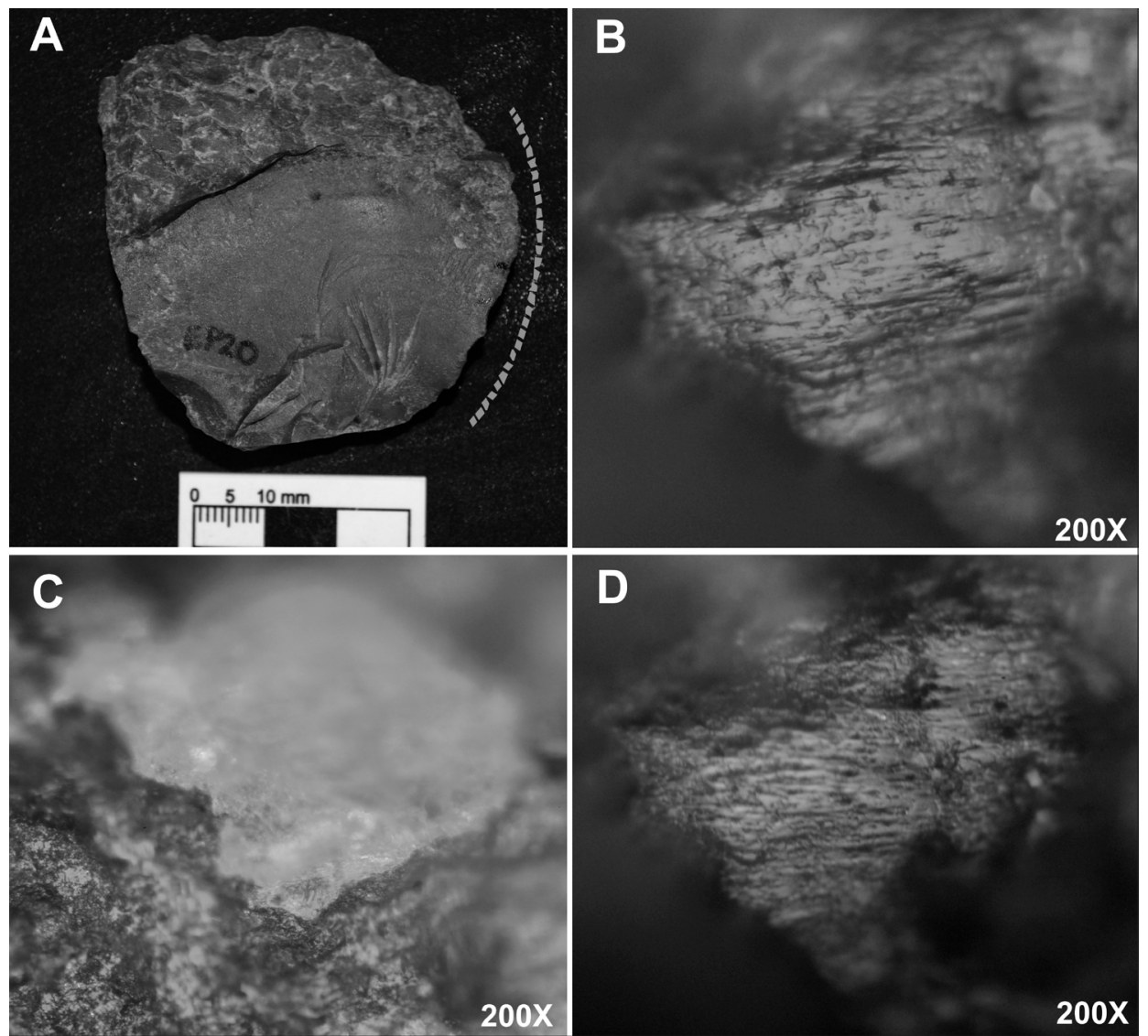

Fig. 6 a. Pieza EP20 trabajada longitudinalmente sobre material óseo en estado fresco (60'). b. Micropulido generado por acción de corte en material óseo en estado fresco, foto sacada a inicios de la experimentación antes de ser introducida la pieza en solución ácida. c. Misma pieza sacada al mes y medio de su inmersión (sectores con cambios en la composición cristalina de la roca). d. Micropulido de material óseo luego de tres meses de inmersión en solución ácida, se notan algunos cambios en el volumen del micropulido pero pudo ser identificado con facilidad el material trabajado (óseo). 
Tabla 3. Cantidad de estatosporas de crisofíceas, fragmentos de valvas indeterminadas (Frag. indet) y valvas enteras en cada una de las muestras de Cueva Maripe. Las muestras con mayor cantidad de diatomeas enteras son la D5-M11 y D5-M12 y el fondo de la cueva (CS).

\begin{tabular}{|ccccccccccccccccc|}
\hline \multirow{2}{*}{ Muestras } & D5 & D5 & D5 & D5 & D5 & D5 & D5 & D5 & D5 & D5 & D5 & D5 & A11 & A11 & A11 & F. \\
& M1 & M2 & M3 & M4 & M5 & M6 & M7 & M8 & M9 & M10 & M11 & M12 & M1 & M2 & M3 & CUEVA \\
\hline Estatosporas & 44 & 101 & 131 & 115 & 99 & 261 & 85 & 11 & 274 & 100 & 242 & 165 & 369 & 11 & 11 & 193 \\
Frag. Indet. & 151 & 25 & 65 & 64 & 22 & 46 & 15 & 14 & 61 & 130 & 269 & 145 & 54 & 13 & - & 47 \\
\hline $\begin{array}{c}\text { Valvas } \\
\text { enteras }\end{array}$ & 169 & 10 & 39 & 54 & 15 & 46 & 23 & 5 & 41 & 39 & 392 & 636 & 58 & 5 & 3 & 386 \\
\hline
\end{tabular}

presencia de agua hacia el interior de la cueva, y en los distintos niveles de ocupación, actuando como un factor importante capaz de ocasionar modificaciones sobre las superficies de las piezas arqueológicas. Por lo tanto, se parte de la premisa de que la presencia de agua podría haber ocasionado cambios en la composición del $\mathrm{pH}$ del sedimento, sumado a un aporte diferencial de la roca de caja sobre todo para los niveles más profundos de ocupación del sitio.

Los estudios realizados permitieron identificar 35 taxones en los distintos sectores de Cueva Maripe, 17 de los cuales se reconocieron sólo a nivel genérico. Dado el bajo grado de preservación del material, en muchos casos se hizo dificultosa la identificación a nivel infragenérico. Las diatomeas registradas son principalmente epífitas, es decir, que se encontraban adheridas a un sustrato. La mayoría de las especies registradas se localizan en aguas alcalinas y sólo algunas se desarrollan en aguas circumneutrales. En general, las especies observadas viven en el agua y también regularmente en lugares húmedos. Las muestras sedimentarias tomadas en el perfil Este de la cuadrícula D5 de la Cámara Norte (correspondientes a la capa más profunda de la excavación - capa 5d-) y en la superficie actual del fondo (parte más interna de la cueva), actualmente, uno de los lugares más húmedos donde se encontró mayor abundancia y diversidad de especies. Entre estas especies fueron identificadas $H$. amphioxys, Nitzschia párvula, Pinnularia borealis y Denticula elegans, especies que colonizan lugares húmedos o con encharcamientos someros y temporarios.

La gran cantidad de valvas fragmentadas sumada a la baja frecuencia de valvas completas dificultóla caracterización de posibles microambientes durante los momentos de ocupación de la cueva tanto en Cámara Norte como en Cámara Sur. Esto se puede vincular con el grado de preservación de las valvas de diatomeas. Es difícil definir una causa probable para la alta fragmentación de los restos silíceos en la Cámara Norte. Sin embargo, varios procesos post-depositacionales como percolaciones, derrumbes del techo, encharcamientos, actividad de roedores y ganado (capas de estiércol de vacas- que producen acidificación en los sustratos superficiales-, pisoteo, etc.) pueden haber afectado la preservación, tanto de las diatomeas como de los materiales arqueológicos (Miotti et al. 2007). Sin embargo, algo distinto ocurrió con las muestras tomadas en los niveles más profundos de la cuadrícula D5 en la Cámara Norte donde se halló mayor diversidad de especies y valvas mejor preservadas. Esto permitió inferir las condiciones ambientales previas a la ocupación humana temprana de la cueva. De acuerdo a la flora diatomológica, con un gran porcentaje de especies perifíticas, la Cámara Norte de la cueva podría haber estado encharcada por aguas someras y quietas antes de su primera ocupación (8.992 \pm 65 años $C^{14}$ A.P.) (Fernández \& Salemme 2012).

La muestra analizada del fondo de la cueva de Cámara Sur también presenta mayor cantidad de diatomeas, propias de ambientes con alta humedad. La presencia de un manantial activo hacia el fondo de esta cámara es una fuente de humedad propicia para el desarrollo de distintas especies de diatomeas; por lo que es probable que, en momentos iniciales de ocupación donde los datos paleambientales indican un incremento de las precipitaciones para el área de estudio (Páez et al. 1999, Borromei, 2003), el manantial podría haber aportado agua modificando el $\mathrm{pH}$ del sedimento $\mathrm{y}$ afectando la preservación de los rastros de uso de los instrumentos líticos (Tabla 3). 


\section{RESULTADOS Y DISCUSIÓN}

Los análisis presentados en este trabajo permitieron avanzar en la comprensión de los conjuntos líticos de Cueva Maripe; en lo que respecta al uso de los instrumentos en el interior de la cueva y en cada cámara en particular, como así también, en cuanto al estado de preservación de las piezas durante el inicio de ocupación del sitio.

Los datos obtenidos a partir del análisis macro y microscópico de los materiales ha permitido determinar diferencias tanto en el uso de cada cámara, como en relación al grado de preservación de los materiales.

En primer lugar, se observa que hacia inicios del Holoceno los conjuntos recuperados en Cámara Sur presentan un mayor número de piezas y variedad de grupos tipológicos. En cuanto a la integridad del conjunto y en relación a los rastros identificados como consecuencia de procesos naturales post-depositacionales, podemos mencionar que, en ambas cámaras, se registró proporciones semejantes de artefactos cuyo uso no pudo ser determinado por alteración. Sin embargo, únicamente en Cámara Sur se observó formación de pátinas blancas y concreciones carbonáticas sobre la superficie de las piezas. El registro de estos rastros únicamente en este sector de Cueva Maripe estaría indicando diversos procesos que habrían actuado luego de la depositación afectando al registro arqueológico de los momentos iniciales de ocupación.

Otro punto importante de mencionar, corresponde al análisis de los rastros de uso identificados en ambos sectores, tanto para los momentos iniciales, como también a lo largo de toda la secuencia de ocupación del sitio (Lynch, 2014). En este sentido, es posible observar que el mayor porcentaje corresponde a materiales duros de origen animal (hueso) como así también vegetal (madera). Este punto permitiría plantear hipótesis alternativas acerca de estos bajos porcentajes que podría estar relacionado a la preservación diferencial de micropulidos. Los resultados obtenidos mediante la experimentación con materias primas correspondientes al área estudiada, registraron una mayor incidencia sobre el micropulido de cuero en medios ácidos, a diferencia de los micropulidos generados por el trabajo sobre materiales duros (hueso y madera) y vegetal no leñoso (gramíneas), los cuáles pudieron ser identificados aún luego de haber estado expuestos a condiciones extremas (alcalinidad, acidez o neutras). El registro de estas observaciones confirmaría que los micropulidos ocasionados por el trabajo sobre hueso y gramíneas tendrían un mejor grado de preservación en diferentes condiciones depositacionales. Las características principales de estos micropulidos (mayor espesor) sería una condición propicia frente a los ataques químicos realizados a nivel experimental.

Asimismo, Plisson \& Mauger (1988) sostienen que las condiciones de $\mathrm{pH}$ muy ácido o básico no son necesarias para que la sílice comience su proceso de disolución, ya que existen varias impurezas del mismo que incluso son solubles si el pH se encuentra en estado neutro (Plisson \& Mauger, 1988, en Burroni et al. 2002). Por otro lado, mencionan que los sectores no utilizados son mayormente susceptibles a ataques químicos que aquellos que presentan desarrollo de micropulidos, principalmente en sectores de fracturas, hoyuelos y estrías, ya que el agua penetra con mayor libertad hacia el interior de la superficie rocosa. Siguiendo a Röttlander (1975), esto podría deberse a que los micropulidos cubren depresiones y la fricción generada por el trabajo elimina salientes de la superficie de la roca, generando superficies más estables y por lo tanto, menos susceptibles a modificaciones. Las observaciones realizadas en este trabajo han permitido sostener esta hipótesis frente a los procesos que ocurrieron durante la experimentación. El desarrollo inicial de la pátina se originó en sectores de depresiones o grietas de la roca y luego se expandió a otras direcciones (Fig.4). Estos sectores presentan rugosidades que podrían retener a mayor tiempo la humedad, y en este caso en particular las soluciones utilizadas en la experimentación, lo que habría funcionado como ambiente propicio para la formación de este tipo de modificaciones. Sin embargo, estudios más específicos (curvas de EDAX para determinar la adhesión o perdida de determinados componentes químicos) y a mayor aumento, mediante un microscopio electrónico de barrido, permitirán dar más sustento y nuevas explicaciones a estas observaciones.

En este sentido y siguiendo a Levi Sala (1993) 
la formación de pátinas es un proceso complejo que probablemente incluya la remoción de material intersticial, precipitación de nuevos cristales o la combinación de ambos. Sin embargo, la formación de pátinas estaría indicada para medios alcalinos y en presencia de carbonato de calcio, condiciones que se dan en el registro arqueológico de Cueva Maripe y en los resultados alcanzados a nivel experimental. Sin embargo, la identificación de cambios de coloración (blanquecina) en determinados sectores de las piezas experimentales utilizadas en soluciones ácidas, indicarían la dificultad para determinar las diferentes causas y condiciones capaces de generar tales modificaciones. Esto podría ser explicado a partir de la exposición de las piezas a condiciones extremas (ácidas o básicas), que generan un proceso de difusión controlada de iones (Purdy \& Clarck, 1987). En este sentido, la formación de patinas puede ser considerada como una combinación de procesos mecánicos como químicos, ya que implica la disolución de la matriz como también una difusión controlada. La disolución de la matriz ocurre cuando las bandas granulares se destruyen y se pierden granos de cuarzo, mientras que la difusión implica la unión selectiva de iones durante la exposición a ambientes ácidos. Ambos procesos contribuyen en la apariencia externa de la superficie rocosa, sin embargo el factor fundamental en estos procesos es la disponibilidad de humedad (Purdy \& Clarck, 1987; Burroni et al. 2002).

Por otro lado y teniendo en cuenta las diferentes alteraciones identificadas (i.e. pátinas blancas y concreciones carbonáticas) a partir del análisis funcional realizado sobre los materiales líticos arqueológicos y los procesos de formación del sitio, es posible plantear algunas cuestiones al respecto del registro arqueológico de Cueva Maripe. En primer lugar, la presencia de un manantial activo en la actualidad en el fondo de la Cámara Sur, indicaría posibles encharcamientos e infiltraciones dentro de la cueva, lo que provocaría un deterioro físico y químico de la roca de fondo. La existencia de éste bajo condiciones ambientales áridas, permitiría suponer que en el pasado con incrementos de la humedad, el mismo, haya estado reactivado con mayor intensidad. En este sentido, se podrían haber formado charcas adentro de la cueva, generando la posibilidad de usos alternados de ambas cámaras (Miotti et al. 2007,
Magnin, 2010). Cabe aclarar que la presencia de cianobacterias epilíticas juega un importante rol en la disolución del carbonato de las rocas, pudiendo provocar el desprendimiento de partes de la misma (Ortega-Calvo et al.1991). La presencia de agua por escurrimiento junto con carbonatos provocaría modificaciones del pH en el sedimento de Cámara Sur, pudiendo alterar de manera diferencial las piezas líticas, viéndose expresado, mediante el análisis macroscópico y funcional, a partir de la identificación de concreción carbonáticas y formaciones de pátinas blancas en las piezas analizadas correspondientes al sector sur de la cueva.

Asimismo, las paredes de Cueva Maripe presentan infiltraciones y canales internos. Tal es el caso de los fogones hallados en la pared Este de la cuadrícula D5, que fue lavado por un canal interno de agua generado por una infiltración proveniente del techo de la cueva. Estas filtraciones pueden ser ácidas o básicas debido a que las rocas sometidas a lavado corresponden a ignimbritas y basaltos. Es sabido que las filtraciones en las cuevas de arenisca son de aguas generalmente ácidas ( $\mathrm{pH}$ : 3,7-6), mientras que las que se filtran entre las paredes de piedra caliza son ligeramente ácidas a alcalinas ( $\mathrm{pH}$ 6,5-8) (Johansen, 2010). Por lo tanto, la variación del $\mathrm{pH}$ (principalmente alcalino en los niveles más profundos de la secuencia) ocasionado por filtraciones y aporte diferencial de la roca de caja, pudo haber generado condiciones particulares de depositación en cada cámara de Cueva Maripe, modificando la preservación de las diatomeas como así también de los materiales arqueológicos, especialmente líticos y por lo tanto, dificultando el reconocimiento de los rastros generados por el uso de estos materiales.

\section{CONSIDERACIONES FINALES}

La génesis de los procesos postdepositacionales que modifican las superficies de los materiales es muy compleja y comprende tanto factores mecánicos; como químicos (presencia o ausencia de agua en el medio, alcalinidad o acidez del sustrato y del agua, presencia de sedimento arenoso o gravoso, entre otros) (Schiffer, 1987; Levi Sala, 1993; Mansur, 1999; Favier Dubois, 2000; Stein, 2001; Burroni et al. 2002, Borrazzo, 2004; 
Martínez, 2007, entre otros). La investigación realizada ha permitido indagar algunas propuestas acerca del origen de estos procesos ocasionados por factores químicos y sus implicancias en el análisis de los rastros de uso de Cueva Maripe hacia inicio del Holoceno. Asimismo, a través del análisis de diatomeas incorporar datos con el fin de dar un mayor sustento a los resultados alcanzados mediante la experimentación. Sin embargo, aún resta por analizar los procesos ocasionados por factores mecánicos y su accionar en el registro arqueológico.

En este sentido, las alteraciones naturales ocasionadas sobre artefactos líticos luego de su depositación pueden influenciar el grado de preservación de los rastros originados por el uso de un instrumento; sin embargo la intensidad en el que actúan estos procesos dependerá del tipo de sedimento y de los procesos microerosivos que sucedan en el sitio. El reconocimiento de cada uno de estos procesos, gestados durante el tiempo de permanencia de los artefactos y la manera en que estos influyen sobre las superficies líticas modificando los rastros de uso, permitirá a pesar de ellos realizar un análisis funcional consistente en los casos donde no hubo destrucción total y secundariamente interpretar los procesos que formaron parte del registro arqueológico.

Por lo tanto, mantener una perspectiva geoarqueológica como tafonómica en el análisis tanto de los artefactos líticos como de otro tipo de material, es de suma importancia a la hora de interpretar el registro arqueológico como reflejo de la actividad humana del pasado.

\section{AGRADECIMIENTOS}

Al Dr. Darío Hermo por las críticas y aportes en la elaboración de este manuscrito, al Lic. Bruno Mosquera por los datos obtenidos del análisis geoarqueológicos de Cueva Maripe y al Lic. Luis Telese por su aporte en los preparados de las soluciones químicas utilizadas. Las autoras de este trabajo queremos agradecer a los integrantes del equipo de la División de Arqueología del Museo de Ciencias Naturales (La Plata) por el apoyo y asistencia logística en el trabajo de campo. El Laboratorio de Diatomeas Continentales (FCEyN, UBA) y Laboratorio de Arqueología de Patagonia
(FCNyM, UNLP) brindó los equipos para procesar la totalidad de las muestras; el Museo de Ciencia Naturales de La Plata (UNLP) junto con el CADICCONICET brindaron el lugar de trabajo. Esta investigación fue financiada parcialmente mediante los proyectos PICT 1552 otorgados a Laura Miotti y PICT 05-38096 otorgados a Mónica Salemme y mediante beca otorgada por el Centro Nacional de Investigaciones Científicas (CONICET).

\section{BIBLIOGRAFÍA}

Álvarez, M. R. (2003). Organización tecnológica en el Canal Beagle. El caso de Túnel I (Tierra del Fuego, Argentina). Tesis doctoral. Facultad de filosofía y letras, Universidad de Buenos Aires. Buenos Aires. MS.

Anderson-Gerfaud, P. (1981). Contribution Methodologique a l'Analyse des Microtraces d'Utilisation sur les Outils Prehistoriques. Tesis Doctoral. Universidad de Bordeaux I, 1604. Bordeaux. MS.

Borrazzo, K. (2004). Hacia una tafonomía lítica. El análisis tafonómico y tecnológico de los conjuntos artefactuales líticos de superficie provenientes de los loci San Genaro 3 y 4 (Bahía San Sebastián-Tierra del Fuego, Argentina). Tesis de Licenciatura inédita. Facultad de Filosofía y Letras, Universidad de Buenos Aires, Buenos Aires. MS.

Borromei, A.M. (2003). Palynology at Piedra Museo locality, Santa Cruz Province, Argentina. Where the South Winds Blow, L. Miotti, M. Salemme, \& N. Flegenheimer (Eds.). Center for the Study of First Americans-Texas A\&M University Press, College Station, 113-119.

Burroni, D., Donahue, R. E., \& Mark Pollard, A. (2002). The Surface Alteration Features of Flint Artefacts as a Record of Environmental Processes. Journal of Archaeological Science, 29, 1277-1287.

Carden, N. (2009). Imágenes a través del tiempo. Arte Rupestre y construcción social del paisaje en la Meseta central de Santa Cruz. Buenos Aires: Ed. Sociedad Argentina de Antropología.

Hermo, D. (2008). Los cambios en la circulación de las materias primas líticas en ambientes mesetarios de Patagonia. Una aproximación para la construcción de los paisajes arqueológicos de las sociedades cazadoras-recolectoras. Tesis doctoral. Facultad de Ciencias Naturales y Museo -UNLP. La Plata. MS.

Hull, K. (1987). Identification of cultural site formation processes through microdebitage analysis. American Antiquity, 52 (4), 851-855. 
Favier Dubois, C. (2000). La geoarqueología y los procesos de formación del registro. Arqueología Contemporánea, 6, 123-141.

Fernández, M., \& Salemme, M. (2012). Diatom analysis in Santa Cruz central massif (Patagonia, Argentina): Preliminary results. En: Southbound. Late Pleistocene Peopling of Latin America. Miotti, L. Salemme, N., \& Goebel, T. (Eds.). Center for the study of the Fisrt Americans, Texas A\&M University Press: 41-46.Texas.

Fernández, M. (2013). Los paleoambientes de Patagonia meridional, Tierra del Fuego e Isla de los Estados en los tiempos de las primeras ocupaciones humanas. Estudio basado en el análisis de diatomeas. Tesis doctoral de la Facultad de Ciencias Naturales -UNLP. La Plata. MS.

Johansen, J.R. (2010). Diatoms of aerial habitats. En: Smol, J.P., \& Stoermer, E.F. (Eds.), The Diatoms: Applications for the Environmental and Earth Science, (pp. 465472). Cambridge: Cambridge University Press.

Kaminska, J., Mycielska-Dowgiallo E., \& K. Szymczak. (1993). Postdepositional Changes on Surfaces of Flint Artifacts as Observed under a Scanning Electron Microscope. En: P. C. Anderson, Beyries S., Otte M. \& Plisson H. (Eds). Traces et Fonction: Les Gestes Retrouvés II (pp. 467-476). Lieja : ERAUL 50 Press.

Keeley, L. H. (1980). Experimental Determination of Stone Tool Uses. En: K. W. Butzer \& L. G. Freeman (Eds), Prehistoric Archeology and Ecology Series. Chicago: University of Chicago Press.

Leipus, M. S. (2006). Análisis de los modos de uso prehispánicos de las materias primas líticas en el Sudeste de la Región Pampeana. Una aproximación funcional. Tesis doctoral de la Facultad de Ciencias Naturales y Museo -UNLP. La Plata. MS.

Levi Sala, I. (1993). Use-Wear traces: processes of development and post-depositational alterations. En P. Anderson, S. Beyries, M. Otte \& H. Plisson (Eds) Traces et Functions: les gestes retrouvés, Vol. 50 (pp. 401416). Lieja: ERAUL Editions.

Lynch, V. (2013). Análisis morfológico-funcional de raspadores líticos del sitio cueva Maripe (Santa Cruz, Argentina). En: A. F. Zangrando, R. Barberena, A. Gil, G. Neme, M. Giardina, L. Luna, C. Otaola, S. Paulides, L. Salgán, \& A. Tivoli (Comps.), Tendencias teórico-metodológicas y casos de estudio en la arqueología de la Patagonia. (pp. 417-424). Buenos Aires: Altuna Impresores.

Lynch, V. (2014). Estudio comparativo de la producción y uso de artefactos líticos en el Macizo del Deseado (Santa Cruz, Argentina). Tesis doctoral de la Facultad de Ciencias Naturales -UNLP. La Plata. MS.

Lynch, V., \& Hermo, D. (2015). Evidence of hafting traces on lithics end-scrapers at Maripe cave site (Santa Cruz, Argentina). Lithic Technology, 40 (1), 68-79.

Magnin, L.A. (2010). Distribuciones arqueológicas en la Meseta Central de Santa Cruz: Implicancias para los estudios de uso del espacio y movilidad de sociedades cazadoras-recolectoras. Tesis doctoral de la Facultad de Ciencias Naturales -UNLP. La Plata. MS.

Mansur-Franchomme, M. E. (1983). Traces d'utilisation et technologie lithique: Exemples de la Patagonie. Thèse de 3ème Cycle, Université de Bordeaux I. MS.

Mansur-Franchomme, M. E. (1986). Microscopie du matériel lithique préhistorique: Traces d'utilisation, altérations naturelles, accidentelles et technologiques. Cahiers $d u$ Quaternaire, n 9. Bordeaux : Ėditions di C.N.R.S.

Mansur-Franchomme, M. E. (1987). El análisis funcional de artefactos líticos. Instituto Nacional de Antropología. Cuadernos Serie Técnica, 1:1-87. Buenos Aires.

Mansur-Franchomme, M. E. (1999). Análisis funcional de instrumental lítico: problemas de formación $y$ deformación de rastros de uso. En: Actas del XII Congreso Nacional de Arqueología Argentina, T. 1: 355-366. La Plata.

Mansur, M. E., Piqué, R., \& Vila, A. (2007). Étude du rituel chez les chasseurs-cueilleurs. Apport de l'ethnoarchéologie des société de la Terre de Feu, dins BEAUNE, S.A. ; (Dir.) : Chasseurs-cueilleurs. Comment vivaient nos ancêtres du Paléolithique supérieur. Méthodes d'analyse et interprétation en Préhistoire, CNRS Éditions, Paris. France.

Martínez G. A. (2007). Procesos de formación de sitios en reparos rocosos de Tandilia. Cazadores - Recolectores del Cono Sur. Revista de Arqueología, pp.: 105-127.

Miotti, L., \& Marchionni, L. (2009). Procesando huesos: entre la Etnografía y la Arqueología. En: M. Salemme, F. Santiago, M. Álvarez, E. Piana, M. Vázquez \& M. E. Mansur (Eds.), Arqueología de la Patagonia. Una mirada desde el último confín. Tomo II, (pp.: 787798). Ushuaia, Tierra del Fuego: Utopías

Miotti, L., Hermo, D., Magnín, L., Carden, N., Mosquera, B., Terranova, E., Marchionni, L., \& Salemme, M. (2007). Resolución e integridad arqueológica en la Cueva Maripe (Santa Cruz, Argentina). En: Morello, F.; M. Martinic, A. Prieto\& G. Bahamonde (Eds.), Arqueología de Fuego-Patagonia. Levantando piedras, desenterrando huesos... y develando arcano, (pp.: 555-568). Punta Arenas : Ediciones CEQUA.

Miotti, L., Marchionni, L., Mosquera, B., Hermo, D., \& 
CERASO, A. (2014). Fechados radiocarbónicos y delimitación temporal de los conjuntos arqueológicos de Cueva Maripe, Santa Cruz (Argentina). Relaciones de la Sociedad Argentina de Antropología XXXIX (2), 509-537.

Mosquera, B. (2014). Análisis geoarqueológico del sitio Cueva Maripe, Macizo del Deseado (Santa Cruz, Argentina). En A. Castro Esnal, M.L. Funes, M. Grosso, N. Kuperszmit, A. Murgo \& G. Romero (Eds.), Entre pasados y presentes IV. Estudios contemporáneos en ciencias antropológicas, (pp. 641-660). Buenos Aires, AINA.

Nami, H. (2011). Fundamentos teóricos y epistemológicos sobre arqueología y tecnología lítica experimental. Arqueología Rosarina Hoy 3 (1), 75-98.

Nash, D. T., \& Petraglia, M. D. (1987). Natural Formation Proceses and the Archaeological Record. En D. T. Nash y M. D. Petraglia (Eds.), British Archaeological Reports / International Series 352, Oxford.

Rabassa, J., Miotti, L., Marchionni, L., Blanco, R.V., \& Salemme, M. (2007). Informe de campaña arqueológica. Excavación y geoarqueología del sitio Cueva Maripe. MS.

Ortega-calvo, J. J., Hernández-Marine, H. \& SaizJiménez, C. (1991). Biodeterioration of buildings materials by cyanobacteria and algae. International Biodeterioration 28, 165-186.

Páez, M. M., Prieto, A.R., \& Mancini, M.V. (1999). Fossil pollen from Los Toldos locality. A record of the Lateglacial transition in the Extra-Andean Patagonia. Quaternary International, 53/54, 69-75.

Pal, N. (2008). Aportes al estudio de la integridad del sitio Laguna La Barrancosa 1 (partido de Benito Juárez, provincia de Buenos Aires): análisis textural y distribucional de los microdesechos líticos. Intersecciones en Antropología $\mathrm{N}^{\circ}:$ 9, 59-75.

Panza, J. L. (2001). Hoja Geológica 44769-IV Monumento Natural Bosques Petrificados. Provincia de Santa Cruz. Boletín 258. Instituto de Geología y Recursos Minerales. Servicio Geológico Minero Argentino, p. 110

Paunero, R S. \& Castro, A. (2001). Análisis lítico y funcionalidad del componente inferior de Sitio Cueva 1, Localidad Arqueológica Cerro Tres Tetas, Provincia de Santa Cruz, Argentina. Anales del Instituto de la Patagonia, 29, 189-206.

Plisson, H. (1983). De la conservation des micro-polish d'utilisation. Bull de la Societe Prehistorique Francaise 80.

Plisson, H., \& Mauger, M. (1988). Chemical and mechanical alteration of microwear polishes: an experimental approach. Helinium XXVII, 1, 3-16.

Purdy, B. A., \& Clarck, D. E. (1987). Weathering of Inorganic materials; dating and other applications. Advances in Archaeological Method and Theory, 11, 211-253.

Rottländer, R. (1975). The formation of patina on flint. Archaeometry 17, 106-110.

Schiffer, M. (1983). Toward the identification of formation processes. American Antiquity 48 (4), 675-706.

Schiffer, M. (1987). Formation Processes of the Archaeological Record. University of New Mexico Press, Alburquerque.

Shepherd, W. (1972). Flint: Its Origin, Properties and Uses. Faber and Faber, London, p. 256.

Stapert, D. (1976). Some natural modifications on flint in the Netherlands. Paleohistoria, 18, 7-41.

Stein, J. K. (2001). A review of site formation processes and their relevance to geoarchaeology. En Goldberg P., Ferring R. y Holliday V. (Eds), Earth Science and Archaeology (pp. 37-51). Nueva York. Kluwer Academic/Plenum Publishers.

Vaughan, P. (1981). Lithic Microwear Experimentation and the Functional Analysis of the Lower Magdalenian Stone Tool Assemblage. Unpublish PhD dissertation, Department of Anthropology, University of Pennsylvania, Philadelphia.

Semenov, S. A. (1964). Prehistoric technology. An experimental study of the oldest tools and artifacts from traces of manufacture and wear. Trans by M.W. Thompson. Monraker Press. 
